\title{
Role and Importance of Educational for Effective Growth of Indian Economy: An Overview.
}

\author{
Sri E. Sreenivasulu \\ M.A., M.Ed., M.Phil (Ph.D) Principal Sri Raghavendra College of Education Allagadda, Kurnool (Dt.) A.P.
}

\begin{abstract}
The Indian education system is presently facing several issues and challenges. Education is a continuous process. It deals with over growing man in ever growing society. The word education originated from the Latin word which means" to bring up". Education should clarify, Man's relation with man, Man's relation with the universe and Man's relation with creator or God.

The importance of Education is today's need as it is the not only the development of intellectual skills and knowledge but also to effective growth and development of Indian Economy. The Education system needs to make students as learners innovators, scholars, researchers and trainers.

In the past century, we progressed from a stage where the application of science to manufacturing techniques become the basis for production and to develop the Indian Economic system. Education has been found a major source of productivity growth in post-war era, and because Education increases productive human capital, It contributes to overall increase in Economic growth, It is estimated that from 1948 to 1973, Education and the innovated accounted for two-thirds of the increase in U.S.

In light of the many Potential benefits of International Trade such as increased sales (or) revenues, cost reductions, technology transfers, the search for higher quality products, industry development, general economic growth of India. Globalizing and Privatization has increased economic competition within and between countries and the world's regions. Economics compositeness is commonly seen as a valid index for judging a country levels of economic Prosperity. Many recent Large - Scale Education reforms have been justified by the urgent need to increase Labour productivity and promote Effective economic development and growth through expanded and improved education.

The concept of effective Growth of Indian Economy is much wider in scope than the Role of Education at covers and higher Level.
\end{abstract}

\section{Introduction}

Globalization has not only increased completion in world economics but also with in and between the education system. Policies and strategies that drive educational reforms have been adjusted to the new realities by creating structures in education systems that allow assessing comparing and rank ordering national and regional education performances. India is a low income developing country. There is no doubt that nearly one fourth of its population lives in conditions of misery. Poverty is not only acute but is also a chronic malady in India.

\section{Meaning}

Education for the knowledge based economy has become a buzz phrase in education policy discourse throughout the developed world and the transition economies but also increasingly in developing countries. Typically, education reform that is targeted on serving knowledge based economics emphasizes mathematics and science, information and communication technologies, basic knowledge and skills in literacy and development of interpersonal skills. More over a successful knowledge economy also requires advanced secondary and tertiary education provision able to boost labour productivity, research and innovation.

\section{Education - classification}

A need quality Education is today's need as it is the development of intellectual skills and knowledge which will equip learners to fulfill the needs of professionals, decision makers and trainers.

The term education is a part of learning which in one sense or another, under the control of men, with the degree of control varying according to circumstances. Therefore the education can be divided into various kinds. 


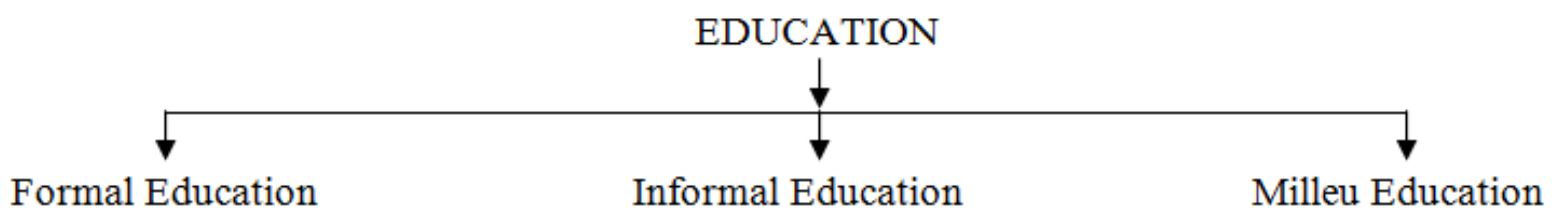

\section{Formal Education}

It is that which is consciously and deliberately planned for the modification of behavious, with a particular predetermined objectives in view.

\section{Informal Education}

It is not pre-planned. It is quite incidental. This education starts from the very birth of child and continues till dearth. In short, it is that modification of behaviour which comes about necessarily and spontaneously, without any conscious effort for it.

\section{Milleu Education :}

This kind of learning that takes place almost automatically, eg to walk on side walks; to eat certain food and to avoid others to live in houses. Milleu education is also known as social contagion.

Education is not as single aim activity. Different aims represent different ways to looking at the same thing. Education aim is to be belongs to vocational, culture and happiness, moral and spiritual. In the past country, we progressed from a stage where the application of science to manufacturing techniques or to agricultural practices become the basis for production. Indian economic competitiveness is the key attribute of economic development and growth. In the knowledge based economics in the last two decades expectations of education, especially the qualities desired in educated and trained people have dramatically changed.

\section{Indian Economy}

India is an under developed though a developing economy. Bulk of population lives in conditions of misery. Poverty is not only acute but also chronic. At the same time, there exist un utilized natural, resources. The co-existence of the vicious circle of poverty with the various circle of affluence perpetuates misery and foils all attempts at removal of poverty. It is in this context that an understanding of the major issues of development should be made.

\section{Education system at Door step}

The idea of education which expects an effective and far researching influence on the impressionable minds of youth should not be alien to the national genius and culture. A glance into the past reveals that never in history has any generation of people seen such radical change in the system of education, as vast, which has affected the life of our ages tremendously. The progress of any country lies on the literacy and education of its population as it gives the required discrete power to judge and rationalize the events on natural surroundings as well as in the social conditions. A good judgment towards these aspects prevails in the mind of the truly educated one. The purpose of education can not be just money making but truly man making. In the light of the above statement, the investigator would like to present the analysis on the four of the effectiveness and growth of the development of Indian Economic System.

\section{Role and importance of Education}

Generally, at the start of a very young age, children learn to develop and use their mental, moral and physical powers, which they acquire through various types of education. Education is commonly referred to as the process of learning and obtaining knowledge at school, in a form of formal education. However the process of Education does not only start in a child first attends school. Education begins at home one does not only acquire knowledge from a teacher, one can learn and receive knowledge from a parent, family member and even as acquaintance. In almost all societies at any school and receiving an education is extremely vital and necessary if are wants to achieve success. However, unfortunately we have places in the world where not every one has an opportunity to receive this formula type of Education. Learning subjects in school is not enough one can learn history, maths, science in school, and the "book smart" inaddition, one can learn how to live life by knowing what to say when, acting a certain way in certain situations and be "street-smart".

The above two types of knowledge are extremely essential to the successful in life. But no matter what, education is the key that allows people to more up in the world, seek better jobs, and ultimately succeed fully in life. Education is very important and to develop the Indian economy systems is very objectively. 


\section{Role of Education in the Economic growth}

The growth of the economy and development of a country is depending upon the education system of that particular country. A perfect and successful batch of youth of a country is come from education sector. Many foreign / abroad countries including India, China, Australia, Newzeeland, Singapore and many other developing moves started to welcome more international students.

As they bring different ideas, culture as well as foreign incomes in the form of fees structure, living expenses and other daily expenses. Where as those developed countries like UK, USA Canada and other developed European countries already open doors for international students and these countries are always emphasis on improving their education structure, developing more colleges and universities on country side areas and always in a way to update their course content on regular. India has also launched many types of different degree courses offered by various universities and colleges of India. But more as times goes on, Indian Education Development has very well improved and now started many programmes and degree courses at International of standard along with the implementation of grading system in middle school that brings relief to middle school students and make them motivated to work hard to complete with co-operate world. The story of education in India is a paradox. Twenty percent of Indian get a fairly decent education, and in a nation of 1.2 billion, this is huge number and helps to explain why India has become the back office of the world. Government schools have failed in India, and this is why one-third of Indians children attend private schools. The Government has implicity recognized its failure and requires that a fourth of the seats in all private schools be reserved for the poor, whose fees are subsidized by the Government.

\section{Trends in Enrolment}

The total enrolment in the education system (excluding distance education) has increased from 0.17 million in 1950-51 to 10.48 million in 2004-05. During the period 1950-51 and 2004-5, while total enrolment at higher education level has increased at an average annual growth rate of 8.04 percent, the growth rate in the total number of teachers has been 5.78 percent. Nearly 87 percent of students in the higher education system are enrolled in the affiliated colleges. In fact, more than 90 percent of graduate and 65 percent of post graduate students are enrolled in affiliated colleges. It is also revealing that only 0.65 percent of students in higher education institutions are engaged in research.

It is a common practice that the priority accorded to education is gauged with the help on indicators like public allocation as a proportion of GNP and budget. It may be noted that India has committed to allocate 6 percent of GNP to education long ago. Issues of quality enhancement should become the priority to reap the benefits of internationalisation of higher education. A pragmatic approach to enhance the equity and access should be given due attention. The quality level of the public and private institutions should be published and brought to the notice of general public. Since the Indian system is ver large, the University Grants Commission cannot monitor all the private institutions. The UGC can frame clear cut policy and ask the different states to institute a separate agency for the purpose as per the guidelines of the UGC.

\section{Concluding Discussion}

Education reforms currently planned or implemental throughout the world need to include deeper and more comprehensive analysis of what and how schools and leaders should do in order to contribute to the development of Indian economic system of the countries. The emergence of the network society and knowledge based economics appear to be a powerful justification for education reforms in developed countries.

Living in and working for a world of innovations requires fundamentally different attitudes, knowledge and skills from the citizens. Technological adaptation and innovation have been the main drivers of economic growth in developed countries sin the world war 2nd and are praying to be important factors also in many developing countries. Successful economic complete on the basis of high values, not only low cost. High value is best guaranteed by well trained and educated personnel and flexible lifelong learning opportunities for all citizens. The most frequently presented general idea for increasing Indian economic development is to equip people with the skills and attitudes success in an increasingly knowledge based economy.

The Indian Economic growth and development is built on three central ideas.

- Economic growth can be analyzed within macro economic environment, the quality of public institutions and technology.

- Technological advance is the ultimate source of growth but its origins may be different across countries.

- The importance of the determinates of economic development for core and non-core innovators.

Based on these commonly used determinants of economic development and growth various indicators of knowledge economy, three core domains have been utilized to explain economic growth.

- Education and training. 
- Use of information and communication technologies.

- Innovations and technological adoption.

In this article I am offering a profound paradox. To prepare themselves for a more competitive economy, our schools and students must compete less. Schools should therefore increase internal collaboration against external competition.

\section{References :}

[1] Agrwal, (2006) : "Higher Education in India": The need for change, Indian council for research on international relations.

[2] Bhargava (2006): "Knowledge and National Development", paper presented in the National seminar on the Education commission organized by NUETA.

[3] Datt \& Sundaram (2007) : "Indian Economy"; Gauravdatt and Ashwani Mahajan, S.Chand and Company Ltd., New-Delhi.

[4] Gupta, Asha (2005) : "International trends in Higher Education on the Indian scenario".

[5] Patel.I.G (2003) : "Higher Education and Economic Development", National and International Perspectives

[6] University Grant Commission (U.G.C) (Various years) annual reports, U.G.C, New-Delhi. 